\title{
ANALYSIS OF RELATIONSHIP BETWEEN LEADERSHIP STYLES AND EMPLOYEE ENGAGEMENT
}

\author{
Anton Vorina ${ }^{1}$ \\ Tina Ojsteršek ${ }^{2}$
}

Received: November 29, 2018 / Revised: January 23, 2019/ Accepted: March 26, 2019

(C) Association of Economists and Managers of the Balkans, 2019

\begin{abstract}
This paper examines the correlation between leadership styles and employee engagement. For the purpose of our research, we have used a random sample of 594 respondents who are employed in both the public and the private sector in Slovenia. The main goal of the research is to contribute to the understanding of how one independent variable (X1- a Dummy variable for Leadership style; XI = 0 mostly or over $50 \%$ of the leaders use the autocratic style of leadership; $X 1=1$ otherwise) impacts the $Y$ variable (employee engagement). Online surveys combined with face-to-face as well as online interviews were carried out from 4 January to 14 March 2016. For statistical analysis, IBM SPSS 20 has been used and linear regression analysis applied. Based on the linear regression $F(1,586)=1.786$, $p$-value $=0.182, R$-square $=0.003)$, we have found out that there is not any statistically significant (at the 5\% significance level) correlation between leadership style and employee engagement. We have also come to a conclusion that autocratic style is mainly used in employee management by Slovenian leaders. Moreover, there is no statistically significant difference at the 5\% significance level in leadership styles that are used between genders.
\end{abstract}

Keywords: leadership style, employee, engagement, linear regressions

JEL Classification J21 $\cdot$ J53 $\cdot$ M12 $\cdot$ M54

This paper was presented at the Second International Scientific Conference on IT, Tourism, Economics, Management and Agriculture - ITEMA 2018 - November 8, 2018, Graz, Austria, www.itema-conference.com

Anton Vorina

anton.vorina@guest.arnes.si

School of Economics, Vocational College, Mariborska 2, 3000 Celje, Slovenia

Jezikovni center Memorija d.o.o., Vizjakova 1, 3202 Ljubečna pri Celju, Slovenia 


\section{INTRODUCTION}

The purpose of this paper is to investigate whether and how one variable (X1- a Dummy variable for Leadership style (LS); X1=0 mostly or over $50 \%$ of the leaders use the autocratic style of leadership; $\mathrm{X} 1=1$ otherwise) influences the dependent variable under study defined as Y-a (employee engagement-EE). The aim of the study is to contribute to the understanding of how one independent variable (X-Leadership style-LS) impacts the Y (employee engagement-EE) variable based on linear regression models.

The main research hypothesis is that the independent variable (X-LS) explains the variation in the dependent variable (Y-EE) and the relationship between the two is statistically significant.

An additional research hypothesis states that Slovenian leaders mostly use the autocratic style for managing employees.

The last research hypothesis states that there is a statistically significant difference in the use of leadership style between genders.

Software programs used for the analysis were IBM SPSS 20 and Excel. The research methods that we applied were the ANOVA test and linear regression model. Research data has been acquired through the use of a questionnaire.

\section{EMPLOYEE ENGAGEMENT}

Kahn (1990, p. 694) was the first academic author to define "personal engagement" as the "harnessing of organization member's selves to their work roles: in engagement, people employ and express themselves physically, cognitively, emotionally and mentally during role performances".

Employee engagement is the ability and willingness of employees to contribute to organizational success, especially their willingness to make ,discretionary efforts” going beyond and above the minimum typically required for their position in order to make the organization successful.

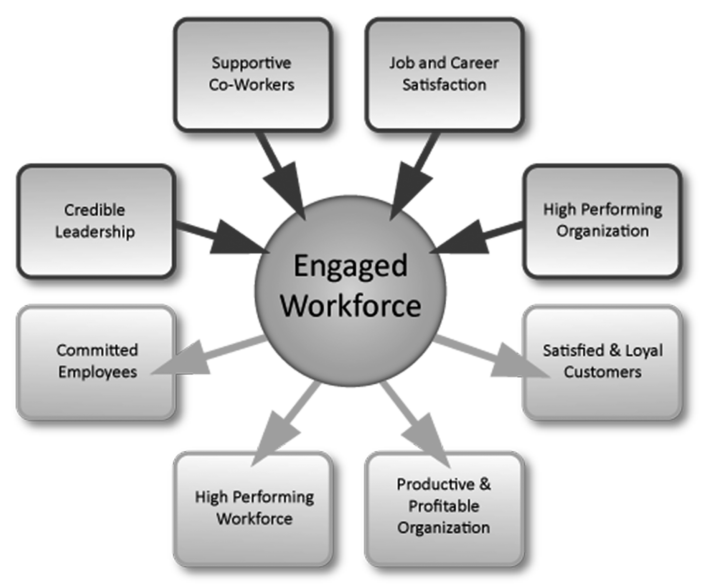

Figure 1: Engaged Workforce

Source: Employee Engagement, http://www.talentkeepers.com/engagement.jsp (10.8.2018). 
The model above (Figure 1) highlights the elements of developing and maintaining an engaged workforce. Employee engagement is an essential element of organizational health. It is the goal of strategic initiatives designed to improve employees' commitment and performance, customer satisfaction and loyalty, as well as the overall productivity and profit of an organization through credible leadership, supportive co-workers, job/career satisfaction, and a high performing organization.

Employee engagement is above all the average willingness to engage the energy and commitment of all employees in everything they do in order to achieve outstanding results.

Furthermore, employee engagement, also called work engagement, is a business management concept. "Employee engagement is a measurable degree of employees' positive or negative emotional attachment to their job, colleagues and organization that profoundly influences their willingness to learn and perform better at work." Work engagement has been defined as "a positive, fulfilling work-related state of mind that is characterized by vigor, dedication, and absorption" (Schaufeli et all, 2006).

Employee engagement is a distinct and unique construct that consists of cognitive, emotional, and behavioural components that are associated with individual role performance (Saks, 2006).

There are differences between attitudes, behavior and outcomes in terms of engagement. An employee might feel proud and satisfied with the job (attitude) and be a loyal advocate of their company to clients, or go the extra mile to finish a piece of work (behavior). Outcomes may include lower accident rates, higher productivity, fewer conflicts, more innovation, higher employee retention rate, reduced sickness rates, satisfied and loyal customers, etc. However, we believe that all three dimensions - attitudes, behavior and outcomes - are part of the engagement story. There is a virtuous circle when the pre-conditions of engagement are met when these three aspects of engagement trigger and reinforce one another. Engaged organizations have strong and authentic values, with clear evidence of trust and fairness based on mutual respect, where two ways promises and commitments - between employers and staff - are understood, and are fulfilled.

The results of a Rathy study (2011) demonstrated a positive relationship between psychological well-being and organizational commitment and its components, namely affective, continuance, and normative commitment.

Vorina (2013) study shows that the engagement of employees would increase if the satisfaction with life increased.

Vorina, David, Vrabič-Vukotić (2013) study shows that if the development of ICT skills increase than also the employee engagement increases.

\section{LEADERSHIP STYLE}

Leadership is an effective approach by which a manager can establish a feeling of mutual goals and unity in a group, thereby ensuring maximum efficiency of the group. To achieve this, a manager needs to have special skills in order to understand individual and group behavior. Democratic leadership is conceptually distinct from positions of authority; rather, it is defined as the performance of three functions: distributing responsibility among the members, empowering group members, and aiding the group's decision-making process. Many, most, or all members of a group serve these functions, regularly exchanging the roles of a leader and a follower (Gastil, 1994). 
Leadership style is considered to be an effective factor for employee performance and business success. In a recent research (Safi et all, 2015) based on a sample of 207 respondents, the authors found that $85.9 \%$ of the heads of health centers use consideration leadership style and managers leadership style. This approach had a positive and significant relationship with job satisfaction of employees (P-value $<0.001$ ) and a negative relationship with job burnout in staff (P-value $<0.001$ ).

The term "leadership" could be explained as a relationship between leaders and followers who undergo transformations and achieve mutual goals (Daft, 2011).

Bergh and Theron (2014) define leadership as a social process in which group processes and behaviors (such as communication and decision-making) play a role. Therefore, leadership is an influence relationship among leaders and followers who intend real changes that reflect their mutual purpose.

\section{METHODOLOGY}

\section{Sample}

For the purpose of this research, we selected population - residents, in a statistical region Savinjska in Slovenia. The investigated unit were people over 16 years old employed in a private enterprise or other institution. The sampling frame consisted of residents from different areas and towns in the statistical region Savinjska. The sample consists of 594 respondents - 251 (42.5\%) men, 339 women $(57.5 \%)$ and 4 respondents $(0.7 \%)$ who did not provide information about their gender. As to the level of education of our respondents, 37 people $(6.2 \%)$ had completed primary school level of education or less, 345 people (58.1\%) had completed secondary school and 206 $(34,7 \%)$ had finished high school level of education or more. There were 6 people $(1 \%)$ who did not define their level of education. The average age of the respondents is 35.82 years (standard deviation 9.66 years). The average salary is $€ 935.35$ net (standard deviation is $€ 339.95$ ).

\section{Questionnaire}

The questionnaire consists of twenty-one closed-ended questions with three questions relating to demographic data (gender, age, level of education and amount of salary) of respondents. We have created a structure of the questionnaire. For the employee engagement measurement, we used the UWES-9 scale. This scale, also called the Utrecht Work Engagement Scale (UWES), is composed of 9 items and was found to have good psychometric properties, with Cronbach's $\alpha$ generally higher than 0.80. The UWES-9 (Schaufeli et all, 2002) questionnaire consists of 9 items: S1. At my work, I feel bursting with energy. S2. At my job, I feel strong and vigorous. S3. I am enthusiastic about my job. S4. My job inspires me. S5. When I get up in the morning, I feel like going to work. S6. I feel happy when I am working intensely. S7. I am proud of the work that I do. S8. I am immersed in my job. S9. I get carried away when I am working. We used the 5 point Likert scale for assessment: 6 - always, 1 - never.

The leadership style was measured with two claims, as shown below:

Please, add percentage points, indicating the level of the leadership style used by your immediate superior (for example $60 \%$ autocratic, $40 \%$ democratic, both the style in common must be $100 \%$ ). ${ }^{3}$

\footnotetext{
$3 \quad$ We studied period of the last 60 days.
} 
Management style by your immediate superior is:

a) Autocratic (all decisions are made by himself) - please add percentage points: (autocratic style): $\%$

b) Democratic (to reach a decision by asking subordinates): please, add percentage points (democratic style): $\%$

c) I don’t know.

\section{Sample and database}

Interviews (face-to-face) were carried out from January 4th, 2016 to March, 14th 2016. We interviewed friends and acquaintances. It took about 5 minutes to fill out the questionnaire. We collected 620 surveys but only 594 were analysed. 26 surveys were highly incomplete (more than half of the responses to the questions were missing), so we excluded them from the further statistical analysis.

\section{Research methods}

The collected data were analysed using the data analysis was made with the use of IBM SPSS, version 20. We have also used the Microsoft tools Word and Excel. Regarding the purpose and objectives of the research, we used ANOVA test and linear regression as statistical methods for quantitative data analysis.

\section{Measurement instrument}

We used the UWES-9 scale to measure employee engagement.

Cronbach's alpha is equal to 0.914 (Tables 1 and 2) which means sufficient reliability for measurement of the employee engagement.

Table 1: Case processing engagement. Source: SPSS 20, Author's creation

\begin{tabular}{|c|c|c|}
\hline & $\mathrm{N}$ & $\%$ \\
\hline Valid & 587 & 98.8 \\
\hline Cases excluded & 7 & 1.2 \\
\hline Total & 594 & 100.0 \\
\hline
\end{tabular}

Table 2: Reliability Statistics, engagement. Source: SPSS 20, Author's creation

\begin{tabular}{|c|c|}
\hline Cronbach's Alpha & N of items \\
\hline 0.914 & 9 \\
\hline
\end{tabular}




\section{FINDINGS OF THE RESEARCH-TEST HYPOTHESES}

The first hypothesis was tested with a model of linear regression. In the model, we chose independent variables (X-LS). The dependent variable (Y-EE) was measured as the sum of 9 factors by UWES-9. The linear regression model (1) with estimated parameters is:

$$
\mathrm{Y}=(37,524+0.984 \mathrm{X})
$$

$\mathrm{n}=586$, R-squared $=0.003$, Adjusted R-squares $=0.001$, Standard Error $=8.89219$. In the Model (Table $3,4,5) 0.3 \%$ of total sum of squares are explained by the estimated model. Variable $\mathrm{X}$ $(\mathrm{p}$-value $=0.182)$ is not statistically significant. The first hypothesis was rejected.

Table 3: Regression Model: $\mathrm{K}=1, \mathrm{n}=586$. Source: SPSS 20, Author's creation

\begin{tabular}{|c|c|c|c|}
\hline $\mathrm{R}$ & R Square & Adjusted R Square & $\begin{array}{c}\text { Std. Error } \\
\text { of the Estimate }\end{array}$ \\
\hline 0.055 & 0.003 & 0.001 & 8.89219 \\
\hline
\end{tabular}

Table 4: Regression Model, F-test. Source: SPSS 20, Author's creation

\begin{tabular}{|c|c|c|c|c|}
\hline Model & Sum of Squares & df & F & Sig. \\
\hline Regres. & 141.198 & 1 & 1.786 & 0.182 \\
\hline Resid. & 46256.557 & 585 & & \\
\hline Total & 46397.755 & 586 & & \\
\hline
\end{tabular}

Table 5: Regression Model: $\mathrm{K}=1, \mathrm{n}=586$. Source: SPSS 20, Author's creation

\begin{tabular}{|c|c|c|c|c|}
\hline & Coeff. & Standard Error & $\mathrm{t}$ - Stat & P-value \\
\hline Inter. & 37,524 & 0.501 & 74.895 & 0.000 \\
\hline $\mathrm{X}$ & 0.984 & 0.736 & 1.336 & 0.182 \\
\hline
\end{tabular}

The second hypothesis states that Slovenian leaders use mostly the autocratic style for managing employees. The hypothesis was checked by descriptive analyses.

Table 6: Descriptive analyses; leadership style. Source: SPSS 20, Author's creation

\begin{tabular}{|c|c|c|}
\hline Leadership style & Mean (\%) & St. deviation \\
\hline Autocratic & 60.01 & 21.14 \\
\hline Democratic & 39.99 & 21.15 \\
\hline
\end{tabular}

The Table 6 indicates, that Slovenian leaders use mostly (in $60.01 \%$ ) the autocratic style for managing employees.

The third hypothesis states that there is a statistically significant difference in the use of leadership style between genders. The hypothesis was checked by ANOVA test.

In the Table 7, we can see $(\mathrm{F}(1,513)=0.334$, p-value $=0.564)$ that there is no statistically significant difference between genders in the use of leadership style. Therefore, the hypothesis was rejected. 
Table 7: Test ANOVA-Leadership style and gender.

Source: IBM SPSS 20, Excel, Author's creation

\begin{tabular}{|c|c|c|c|c|c|}
\hline & Sum of Squares & df & Mean Square & F & P-value \\
\hline $\begin{array}{c}\text { Between } \\
\text { Groups }\end{array}$ & 150.057 & 1 & 150.057 & 0.334 & 0.564 \\
\hline Within Groups & 230008.615 & 512 & 449.236 & & \\
\hline Total & 230158.671 & 513 & & & \\
\hline
\end{tabular}

\section{CONCLUSION}

In this paper, we investigated the relationship between leadership style (X-LS) and the dependent variable $\mathrm{Y}$ - EE-employee engagement.

We found out that there is no correlation between employee engagement and leadership style.

Linear regression Model, with $\mathrm{n}=586$ and $\mathrm{K}=1$ regressor indicated that the relationship between the variables $\mathrm{X}$ and $\mathrm{Y}$ is not statistically significant at $5 \%$ significance level. We also found that there is no statistically significant difference between genders and the use of leadership style. Furthermore, we also found that Slovenian leaders used mostly $(60 \%)$ the autocratic style to manage employees.

For further research, it would be interesting to include more independent variables such as level of education, amount of salary, etc. in the linear regression model.

$$
\text { Employee engagement } \neq \mathrm{f} \text { (leadership style) }
$$

\section{REFERENCES}

Andries, P. and Sukesh, S. (2014). The Role of HRM in Leadership Development, Talent Retention, Knowledge Management, and Employee Engagement. Proceedings of World Business and Economics Research Conference 24 - 25 February, 2014, Rendezvous Hotel, Auckland, New Zealand. 1-18.

Daft, RL. (2011). The leadership experience. Cengage Learning. The Leadership Quarterly, 19: 635-653.

Employee Engagement, http://www.talentkeepers.com/engagement.jsp (10.8.2018).

Gastil, J. (1994). A Definition and Illustration of Democratic Leadership. Human Relations. 47(8): 953-975.

Kahn, W. A. (1990). Psychological conditions of personal engagement and disengagement at work. Academy of Management Journal, 33 (4): 692-724.

Rathi, N. (2011). Psychological Well-Being and Organizational Commitment: Exploration of the Relationship. Working Paper No.106/2011, http://www.amrita.edu/sdg/pdf/ASB\%20 Working\%20paper\%20series/MBA\%20book\%20106-2011\%20Psychological\%20WellBeing\%20and\%20Organizational\%20Commitment\%20Exploration\%20of\%20the $\% 20$ Relationship.pdf (6.8.2018).

Safi MH, Mohamadi F, Amouzadeh, I. and Arshi SH. (2015). The Relationship between Managers' Leadership Style with Job Satisfaction and Burnout in Staff of Shomal Health Center of Tehran. Community Health: 2 (2): 88-97. 
Saks, A. M. (2006). Antecedents and consequences of employee engagement. Journal of Managerial Psychology, 21 (7): 600-619.

Schaufeli, W.B., Bakker, A.B. and Salanova, M. (2006). The measurement of work engagement with a short questionnaire: a cross-national study. Educational and Psychological Measurement, 66 (4): 701-716.

Schaufeli, W.B., Salanova, M., Gonzalez-Roma, V. and Bakker, A.B. (2002). The measurement of engagement and burnout and: a confirmative analytic approach. Journal of Happiness Studies, 3: 71-92.

Vorina, A. (2013). The relationship between satisfaction with life and employee engagement. Journal of Process Management - New Technologies, International, 1 (2): 77-81.

Vorina, A., David, K. and Vrabič Vukotić, A. (2013). The relationship between the development of the ICT competencies and employee engagement. Vesnik, 2 (1): 37-50. 